\title{
FIBRAS DE VIDRO: CARACTERIZAÇÃO, DISPOSIÇÃO FINAL E IMPACTOS AMBIENTAIS GERADOS
}

\section{GLASS FIBER: CHARACTERIZATION, DISPOSAL AND ENVIRONMENTAL IMPACT GENERATED}

\author{
Pedro Daniel da Cunha Kemerich ${ }^{1}$ Maurício Piovesan², Luísa Lima Bertoletti ${ }^{2}$, Sabrina \\ Altmeyer ${ }^{2}$, Tatiane HohmVorpagel ${ }^{2}$. \\ 1Professor do curso de Engenharia Ambiental-UFSM, campusFrederico Westphalen. Email: \\ eng.kemerich@yahoo.com.br \\ 2Acadêmicos do curso de Engenharia Ambiental-UFSM, campus Frederico Westphalen. Email:maurício- \\ 182@hotmail.com
}

http://dx.doi.org/10.5902/223611707590

\begin{abstract}
RESUMO
É de extrema importância que o crescente desenvolvimento das empresas e indústrias ande em linha tênue com a sustentabilidade. Ações sustentáveis permitem que pouco ou nenhum resíduo seja disposto em local potencialmente prejudicial ao meio ambiente, sendo que estes devem ser acompanhados e/ou gerenciados de forma que possam ser reduzidos, reaproveitados ou reciclados. O plástico constitui a principal parcela de lixo encontrado em aterros sanitários, e esse número só tende a aumentar. O Plástico Reforçado com Fibra de Vidro (PRVF) tem sido mundialmente utilizado na fabricação de diversos produtos por ser um material de baixo custo e altamente eficiente. O PRVF desperta o interesse das indústrias, porém, também constitui uma ameaça, pois possui uma baixa degradabilidade, chegando a gerar até 13 mil toneladas de resíduos por ano devido a imperfeições nos projetos. Outro aspecto negativo está na sua constituição, uma vez que este possa conter resinas tóxicas ao meio ambiente e a saúde dos trabalhadores envolvidos. Neste sentido, o presente trabalho visa apresentar informações a respeito deste tipo de material, dentre elas a possibilidade de reciclagem, a ameaça ao meio ambiente e as etapas de fabricação do produto.
\end{abstract}

Palavras-chave: Contaminação, rejeitos, poluição ambiental, reciclagem.

\begin{abstract}
:
It is extremely important that the increasing development of businesses and industries in walk fine line with sustainability. Sustainable actions that allow little or no waste is disposed in a potentially harmful to the environment, and these should be monitored or managed so that they can be reduced, reused or recycled. The plastic is the main plot of waste found in landfills, and that number will only grow. The Fiber Reinforced Plastic Glass (PRVF) has been used worldwide in the manufacture of various products to be a material of low cost and highly efficient. The PRVF arouses the interest of industries, but also poses a threat because it has a low degradability, reaching generate up to 13 tons of waste per year due to imperfections in the projects. Another negative aspect is its constitution, since it can contain toxic resins to the environment and health
\end{abstract}


Rev. Elet. em Gestão, Educação e Tecnologia Ambiental (e-ISSN: 2236-1170)

of the workers involved. In this sense, the present study aimed to gather information regarding this type of material, among them the possibility of recycling, the threat to the environment and the steps of manufacturing the product.

Keywords: Contamination, waste, pollution, recycling.

\section{INTRODUÇÃO}

Com o crescente aumento da produção e do consumo mundial de produtos industrializados, a reciclagem de materiais tornou-se uma das mais importantes atividades de controle ambiental, agregando valores econômicos e desenvolvimento tecnológico. Dados atuais confirmam que atualmente, de todo o lixo produzido, os resíduos provenientes do comércio e da indústria chegam à cerca de $50 \%$ da composição dos aterros sanitários (ARAÚJO et al, 2004).

Nos últimos anos, o plástico tem sido misturado com outros tipos de materiais, com determinados aditivos e/ou cargas, recebendo o nome de compósitos, e dessa forma dificultando sua reciclagem (ZATTERA et al, 2000)

A mistura de um reforço (fibra de vidro) a uma matriz polimérica (resina poliéster ou outro tipo de resina) e a uma substância catalisadora de polimerização forma um compósito denominado Plástico Reforçado com Fibra de Vidro (PRFV), cuja técnica permite a produção de peças com grande variedade de formatos e tamanhos: piscinas, caixas d'água, cascos e hélices de barcos, carrocerias de veículos e outras. Porém, no processo de fabricação de compósitos, são geradas grandes quantidades de rejeitos ou sobras, prejudicando o meio ambiente (ORTH et al, 2012).

Por conta da não-degradabilidade natural da maioria dos PRFV esses materiais têm sido responsáveis por sérios problemas ambientais, pois o petróleo é o principal constituinte na fabricação desses plásticos. Outro agravante está na geração de resíduos durante o processo de laminação de um PRFV (LEITE, 2003).

Segundo Orth (2012) "a indústria de compósitos no Brasil gera cerca de 13 mil toneladas de resíduos por ano, entre aparas e rebarbas de processos e peças defeituosas." A maioria desses resíduos vai parar nos aterros industriais, levando-se em conta que as montadoras de veículos são tidas como as principais contribuintes para essa expressiva quantidade de resíduos (SILVA, 2003).

Um fator a ser considerado é a complexidade da reciclagem do PRFV, pois a infusibilidade da resina empregada como matriz dificulta o seu reprocessamento, ou seja, o PRFV não é passível de ser derretido ou remodelado como a maioria dos plásticos (JOSHI, 2003).

De acordo com Wambua et al (2003), "o PRVF suporta altas temperaturas, porém, sofre carbonização, sem derreter quando exageradamente aquecido".

Deste modo, o presente trabalho tem como objetivo reunir informações sobre as fibras de vidro, compreendendo sua composição, os impactos gerados durante a produção e do descarte inadequado, além de apresentar opções de reaproveitamento das mesmas na construção civil.

\section{Fibras de vidro}

A produção de fibras de vidro teve início na antiga Síria, Grécia e Egito. A aproximadamente 250 a. C artesãos começaram a produzir as fibras através de uma vara de vidro aquecida para aplicar como relevo sobre a superfície de produto acabados. Comercialmente, a fibra de vidro 
Rev. Elet. em Gestão, Educação e Tecnologia Ambiental (e-ISSN: 2236-1170)

começou a ser desenvolvida no ano de 1939, no decorrer da 2a Guerra Mundial, com o intuito de fornecer rigidez e leviandade aos equipamentos bélicos (OTA, 2004).

Atualmente, as fibras de vidro são aplicadas em mais de 35.000 produtos, sendo que as mais utilizadas são as do tipo $E$ (E-glass). Essas fibras são obtidas a partir de uma mistura de óxidos de $\mathrm{Si}, \mathrm{Al}, \mathrm{B}, \mathrm{Ca}$ e $\mathrm{Mg}$ e são normalmente usadas como reforços para termoplásticos devido ao seu baixo custo (OTA et al, 2004).

Este tipo de material é composto por filamentos muito finos de vidro, que se agregam por meio de aplicações de resinas, silicones, fenóis e outros compostos solúveis em solventes orgânicos. Ela também recebe outra substância catalisadora que pode conter óxidos de potássio, ferro, cálcio e alumínio (SOARES et al, 2007)

Basicamente, um compósito é considerado como sendo um material multifase que demonstra uma significativa proporcionalidade de ambas as fases constituintes, gerando assim outra fase de melhor qualidade (PINTO, 2002).

Existem muitos grupos de vidros, por exemplo, a sílica, o exinitrito e o fosfato, porém, a silíca é a mais importante para uso em compósitos (MATTHEWS \& RAWLINGS, 1994). A fibra do tipo $\mathrm{S}$ (S-glass - strength) ou tipo $\mathrm{R}$ na Europa, é baseada no sistema dióxido de silício $\left(\mathrm{SiO}_{2}\right)$ óxido de alumínio $\left(\mathrm{Al}_{2} \mathrm{O}_{3}\right.$ - e óxido de magnésio $(\mathrm{MgO})$, esta fibra tem uma alta resistência em relação a fibras do tipo E (MATTHEWS \& RAWLINGS, 1994).

De acordo com Matthews e Rawlings (1994), as fibras são facilmente produzidas por aquecimento do vidro e por moldagem com forças gravitacionais a partir de um mandril de platina. O mandril contém aproximadamente 200 canais e então 200 fibras de diâmetro de 10 microns são feitas simultaneamente.

Fibras de vidro possuem geralmente de 5 a 20 microns de diâmetro e suas superfícies não são livres de falhas, além de estarem intrinsicamente ligadas a irritações na pele humana (WAMBUA et al, 2003). Estas fibras são usadas para reforçar matrizes poliméricas, de modo a se obter compósitos estruturais e componentes moldados. Os compósitos de matriz plástica reforçada com fibras de vidro (figura 1) apresentam as seguintes características favoráveis: elevado quociente entre resistência e peso, boa estabilidade, boa resistência ao calor, à umidade e á corrosão, facilidade de fabricação e custo relativamente baixo. Por esse motivo é de longe o reforço mais utilizado (BARCELLOS, 2009). 


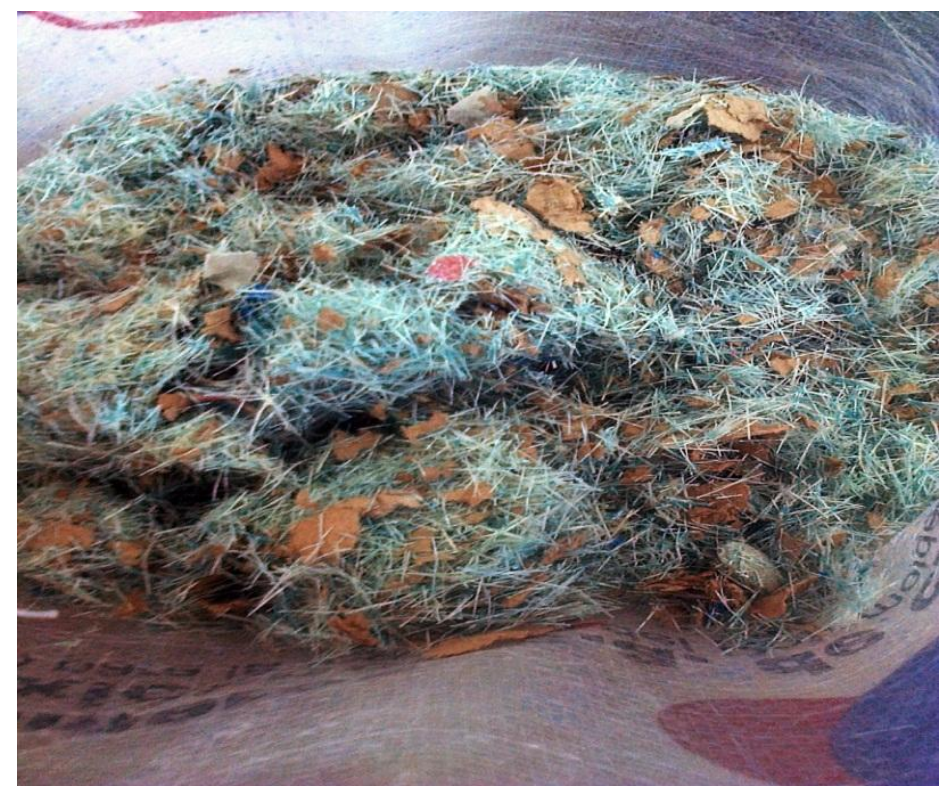

Figura 1. Fibras de vidro.

Fonte: do autor.

\subsection{Matrizes poliméricas}

Polímeros são cadeias de moléculas longas, do grego "poli" ("muitos") e "meros" ("partes"). Já o termo "plástico", é usado para uma grande variedade de polímeros com características e aplicações diferentes. Costuma-se usar frequentemente o termo "polímero" como sinônimo para plástico, porém, o termo não se limita apenas a estas moléculas, com isso pode-se afirmar que todos os plásticos são polímeros, mas nem todos os polímeros são plásticos (PINTO, 2002).

Segundo Pinto e Miranda (1999), os polímeros podem ser classificados como:

1. Termoplásticos: polímeros que, quando aquecidos até o ponto de fusão, podem fluir. Possuem cadeia polimérica linear ou ramificada;

2. Termofixos: estes sofrem uma reação química e formam ligações cruzadas, as quais dão origem a uma estrutura tridimensional. A cura deste tipo de resina ocorre a frio ou a quente. Depois que eles foram conformados, estes não podem ser aquecidos e reconformados.

Dentre os polímeros, o mais utilizado na produção de peças em compósito de matriz polimérica é o poliester insaturado. Este é um termofixo e tem sua estrutura química diferente dos políesteres termoplásticos, pois, além da típica ligação éster, ele possui duplas ligações insaturadas capazes de reagir com monômeros vinílicos. As duplas ligações da resina e do monômero são quebradas pela ação de um catalisador (peróxido orgânico, calor ou radiação), e reagem novamente entre si, dando origem a um polímero tridimensional de características termofixas, e portanto infusíveis e irreversíveis (KELLY, 2002).

$O$ poliéster insaturado pertence às resinas ortoftálicas representada pela figura 2 , isoftálicas, bisfenólicas e tereftálicas (WAMBUA et al, 2003). 


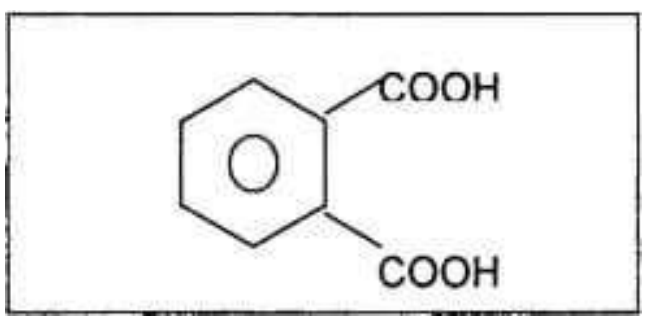

Figura 2. Estrutura molecular do ácido ortoftálico. Fonte: Pinto (2002)

As resinas ortoftálicas possuem baixa resistência a determinados ambientes, entre eles meios ácidos e alcalinos, além de uma suscetibilidade ao calor. Porém, quando devidamente formuladas, têm propriedades mecânicas muito boas. Dentre todas as variedades de resinas de poliéster, são as mais utilizadas, sendo empregadas inclusive em aplicações estruturais (PINTO; MIRANDA, 1999).

As matrizes poliméricas consistem basicamente de uma resina polimérica como fase matriz e fibras como meio de reforço. As fibras de vidro são as mais utilizadas para o reforço de plásticos devido a características como: baixo coeficiente de dilatação, resistência ao impacto e baixo custo (ARAÚJO et al, 2003).

\subsection{Processos de fabricação}

Geralmente os processos de fabricação de compósitos são principalmente do tipo molde aberto, porém, existe também o molde fechado. Em processos de molde aberto, uma das faces da peça fica em contato com o molde, criando um aspecto rústico na outra face. Caixas d'água, assentos, piscinas, tubos, tanques de armazenagem e pás de ventilador são exemplos de processos de molde aberto, sendo produzidos principalmente pelo método da laminação contínua (PINTO; MIRANDA, 1999).

A laminação contínua é principalmente utilizada para a fabricação de telhas. Este método consiste na deposição de resina sobre um filme contínuo. Simultaneamente, as fibras de vidro são picadas e espalhadas sobre a resina, recebendo em seguida mais uma camada de filme contínuo. Este conjunto entra na estufa, onde começa o processo de cura da resina e conformação da peça, a qual se dá a partir de perfis colocados ao longo da estufa. Na saída da estufa ocorre o corte das peças nas dimensões padrão, havendo o corte de rebarbas e a inspeção visual, onde são descartadas as peças que possuírem bolhas ou outras imperfeições (PINTO, 2002).

Em comparação, o processo de molde aberto tem um baixo custo de fabricação e facilidade de correção de erros, porém, é difícil controlar a distribuição uniforme da resina e uma alta emissão de estireno, além de serem gerados mais resíduos (WAMBUA et al, 2003). 


\subsection{Custo benefício}

Por apresentarem boas propriedades mecânicas específicas, aliadas ao baixo custo relativo de fabricação, os compósitos de matriz polimérica são competitivos dentro do mercado, substituindo materiais convencionais, tais como madeira e metal (PINTO, 2002).

A produção de compósitos de matriz polimérica, por se constituir de um produto relativamente de baixo custo, "permite" fatores como a falta de treinamento do operador, especialmente em processos de produção manuais, além de manuseio e utilização inadequada das matérias-primas (WAMBUA et al, 2003).

Sendo assim, o PRVF é tratado com descuido, gerando enormes quantias de resíduos decorrentes de rebarbas e falhas do projeto.

$\mathrm{Na}$ figura 3, são apresentados exemplos de produtos que utilizam fibra de vidro como matéria prima.

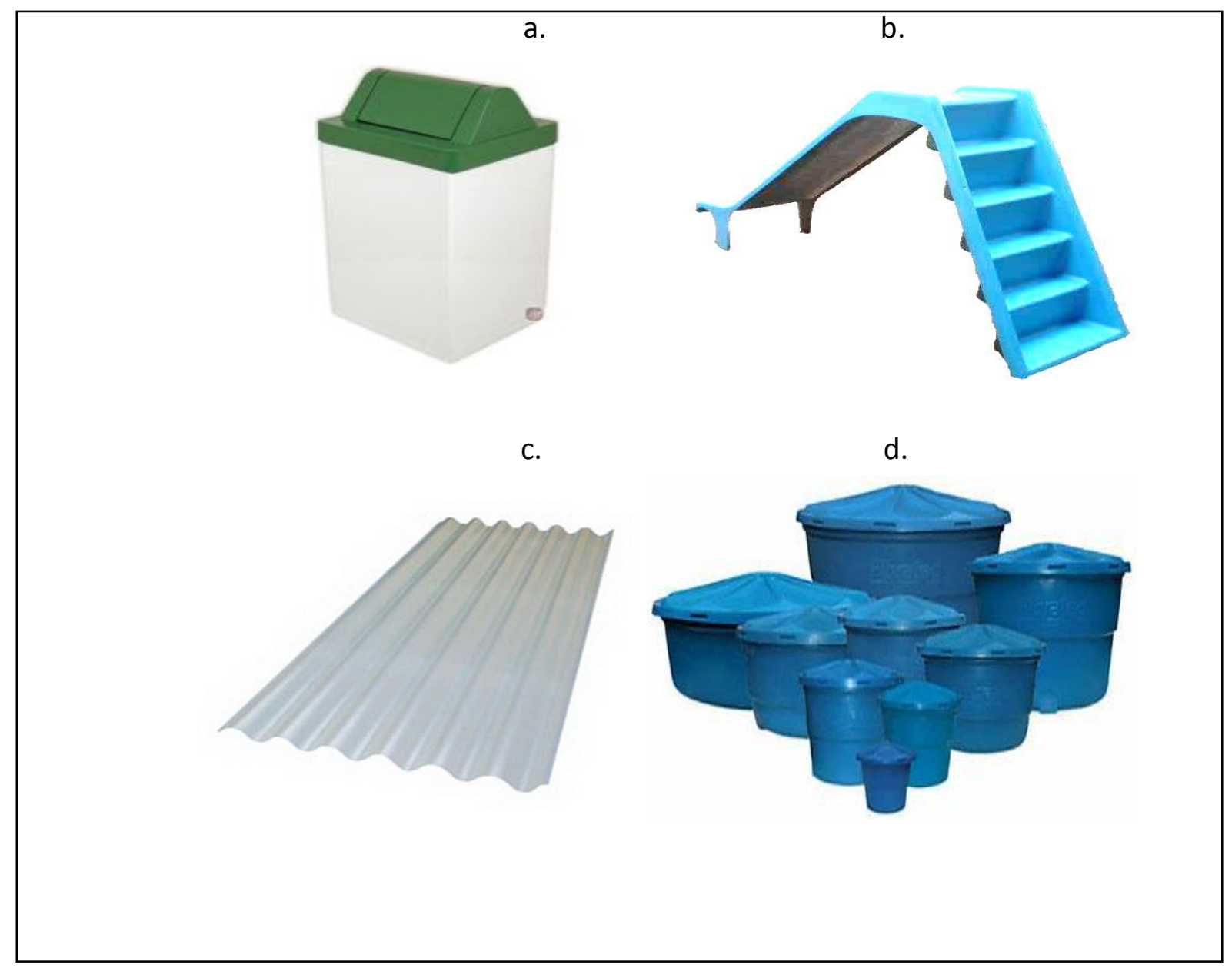

Figura 3. a) Lixeira em fibra de vidro; b) Escorredor em fibras de vidro; c) Telhas translúcidas em fibra de vidro;

d) Caixas d'água feitas com fibra de vidro. Fonte: www.metalpan.com.br. 
Rev. Elet. em Gestão, Educação e Tecnologia Ambiental (e-ISSN: 2236-1170)

\subsection{Composição do resíduo}

A composição do resíduo de PRFV depende do tipo de processo de fabricação do qual o mesmo provém, seja ele de molde aberto ou fechado. 0 quadro 1 abaixo mostra a composição química do resíduo determinada por espectroscopia de fluorescência de raios- $X$ em estudo realizado por Pinto (2002) para a incorporação deste material na construção civil.

Quadro 1. Composição química do resíduo de PRFV. Fonte: Pinto (2002).

\begin{tabular}{|c|c|c|c|c|c|}
\hline Componentes & Unidade & Composição & Componentes & Unidade & Composição \\
\hline $\mathrm{C}$ & $\%$ & 83,73 & $\mathrm{Sr}$ & $\mathrm{Ppm}$ & 123 \\
\hline $\mathrm{Si}$ & $\%$ & 5,88 & $\mathrm{P}$ & $\mathrm{Ppm}$ & 108 \\
\hline $\mathrm{Ca}$ & $\%$ & 7,33 & $\mathrm{~S}$ & $\mathrm{Ppm}$ & 73 \\
\hline $\mathrm{Al}$ & $\%$ & 1,22 & $\mathrm{Mn}$ & $\mathrm{Ppm}$ & 39 \\
\hline $\mathrm{B}$ & $\%$ & 0,88 & $\mathrm{Zr}$ & $\mathrm{Ppm}$ & 37 \\
\hline $\mathrm{Mg}$ & $\%$ & 0,59 & $\mathrm{Zn}$ & $\mathrm{Ppm}$ & 38 \\
\hline $\mathrm{K}$ & $\%$ & 0,11 & $\mathrm{Ni}$ & $\mathrm{Ppm}$ & 19 \\
\hline $\mathrm{Fe}$ & $\mathrm{Ppm}$ & 1068 & $\mathrm{As}$ & $\mathrm{Ppm}$ & 11 \\
\hline $\mathrm{Na}$ & $\mathrm{Ppm}$ & 414 & $\mathrm{Rb}$ & $\mathrm{Ppm}$ & 10 \\
\hline $\mathrm{Ti}$ & $\mathrm{Ppm}$ & 260 & $\mathrm{~Pb}$ & $\mathrm{Ppm}$ & 15 \\
\hline $\mathrm{Ci}$ & $\mathrm{Ppm}$ & 195 & $\mathrm{Cu}$ & $\mathrm{Ppm}$ & 15 \\
\hline $\mathrm{Co}$ & $\mathrm{Ppm}$ & 135 & $\mathrm{Cr}$ & $\mathrm{Ppm}$ & 40 \\
\hline
\end{tabular}

Segundo Pinto (2002), na porcentagem em que os elementos boro e alumínio se apresentam, há o indicativo de que estes são essencialmente provenientes da composição das fibras de vidro do tipo E (aluminio-boro-silicato). O silício, cálcio, magnésio e potássio provavelmente fazem parte da composição das fibras de vidro. Já a presença de cobalto na composição do resíduo deve-se ao acelerador de cobalto utilizado na catálise da resina de poliéster insaturado.

\subsection{Impactos ambientais}

Atualmente, na região da serra gaúcha, vê-se crescer o acúmulo de resina poliéster reforçada com fibra de vidro, atingindo a marca de 80 toneladas por mês, o que vem gerando grande transtorno quanto ao depósito em aterros locais e inutilização de matéria prima. A facilidade em obtenção destes compósitos tem gerado problemas ambientais, pois há a geração de grandes quantidades de rebarbas na fabricação das mantas de fibra de vidro (FONTAN, 2009).

A composição básica dos laminados é de 70 a $75 \%$ de resina poliéster insaturada e de 30 a $25 \%$ de fibra de vidro. Porém, testes de calcinação demonstraram que no resíduo, a proporção é 
Rev. Elet. em Gestão, Educação e Tecnologia Ambiental (e-ISSN: 2236-1170)

praticamente o inverso, com aproximadamente $70 \%$ de fibra de vidro e $30 \%$ de resina (GRIJÓ \& BRUGGER, 2011). Segundo Silva (2010) "esta variação ocorre devido à forma de confecção do laminado, pois o refugo é composto principalmente pelas rebarbas geradas no processo".

Segundo Fontan (2009) "os resíduos gerados contêm elevados teores de cargas minerais, porém fibra de vidro e resina em menor proporção". Já Joshi et al (2003) afirma que "a fibra de vidro em sua forma original é um material seguro, mas quando tratada, ela recebe metais pesados, como o cromo, tornando-se tóxica".

O principal problema se daria no momento da produção da fibra de vidro, quando trabalhadores podem entrar em contato direto com o material ou com seus fragmentos, irritando olhos, pele, nariz e garganta. Altos níveis de exposição a fragmentos de fibra de vidro podem agravar asmas e bronquites. Cerca de $80 \%$ das dermatoses ocupacionais são produzidas por agentes químicos como solventes e resinas que são amplamente utilizados pela indústria de compósitos. Além dos problemas ambientais, um dos principais riscos diz respeito ao "pó de fibra" resultante do manuseio e do corte da própria fibra ou do compósito. Esse "pó" pode causar irritações temporárias (JOSHI, 2003).

Outro problema relacionado à laminação de PRFV refere-se às emissões de estireno durante o processo de fabricação. $O$ estireno e alguns produtos fabricados a partir dele, dentre eles a resina poliéster usada na laminação dos PRFV, são muito voláteis e liberam vapores tóxicos prejudiciais à saúde. As vias de entrada no organismo podem ser: inalação, olhos e pele. Na pele, pode causar irritações futuras. Se inalado, a superexposição pode causar irritação do sistema respiratório e outras membranas mucosas. Quando em contato com os olhos, pode causar irritação moderada, incluindo sensação de queima, lágrimas, vermelhidão ou inchaço. A exposição repetira ou prolongada ao estireno pode causar ainda, nauseas, perda de apetite, depressão do Sistema Nervoso Central e debilidade geral (ORTH, 2012).

No processo de fabricação de pranchas de surf, por exemplo, para produzir o laminado da prancha, a fibra de vidro é misturada com uma resina de poliéster, usada em conjunto com um solvente muito corrosivo (estireno). Esse solvente é cancerígeno e classificado como composto orgânico volátil, contribuinte da poluição atmosférica (GRIJÓ \& BRUGGER, 2011).

Araujo et al (2004) afirma que "quando um composto destes é usado para tratar a resina, seus vapores são liberados e seus componentes incorporados à resina tratada, portanto, estes componentes continuarão sendo eliminados durante o processo de decomposição".

\subsection{Tentativa de reciclagem do PRFV}

Estudos têm sido realizados para verificar a possibilidade do reaproveitamento deste compósito, reincorporando-o ao próprio processo produtivo. Outra possibilidade é a moagem destas rebarbas para utilização na construção civil. Segundo Theodorakopoulos (1995) "a adição de fibra em compósitos de cimento, produz uma melhora no desempenho das argamassas e concretos em relação aos cimentos convencionais". Há pelo menos 30 anos a utilização da fibra de vidro como reforço para pastas de cimento vem sendo estudada, devido as suas propriedades mecânicas como leveza e resistência ao fogo (PINTO, 2002).

Segundo Pinto (2002), "este resíduo apresenta potencial de aplicação nos diversos nichos da indústria de cerâmica vermelha". A aplicabilidade do material particulado, obtido a partir da moagem do resíduo de telhas de PRFV em massa de cerâmica vermelha, se justifica, pois se obtêm uma mistura homogênea e de fácil moldagem. Os resultados dos testes se enquadram aos limites 
Rev. Elet. em Gestão, Educação e Tecnologia Ambiental (e-ISSN: 2236-1170)

especificados para tijolos de alvenaria e furados, telhas e revestimentos cerâmicos (GRIJÓ \& BRUGGER, 2011).

Um impasse no processo de incorporação do resíduo de PRVF na construção civil seria o custo para a moagem do resíduo, porém, conforme verificado, este custo se assemelha ao de transporte para o descarte em aterros sanitários. Garantindo desta forma a viabilidade do trabalho, além, é claro, de promover o desenvolvimento sustentável, conciliando as partes sociais, ambientais e econômicas em torno de uma única causa (ORTH, 2012).

A necessidade de promover um equilíbrio com o meio ambiente justifica as pesquisas de reincorporação/reutilização de materiais. É de fundamental importância frear o uso de matéria prima que não seja a de reúso. Existem muitos resíduos capazes de satisfazer necessidades básicas da humanidade e que deverão ser fonte de estudo com intuito de reutilização dos mesmos

\section{CONSIDERAÇÕES FINAIS}

Com base no tema exposto concorda-se que a fibra de vidro é extremamente útil e possui um grande mercado na indústria de materiais, porém, deve-se atentar também aos perigos que os compósitos de fibra de vidro possam representam ao meio ambiente em geral, de modo que os resíduos gerados durante o processo devam ser reduzidos e reutilizados para evitar o acúmulo em aterros e lixões.

Uma alternativa interessante para as fibras de vidro está na reincorporação destas na construção civil, através da moagem dos resíduos gerados no processo e a incorporação destas em argamassas, ou até mesmo na construção de calçamentos. Estudos foram realizados neste campo e os resultados mostraram-se satisfatórios devido às características físicas da fibra de fibro como a baixa inflamabilidade e alta resistência aos impactos.

Outra medida que deve ser tomada é a otimização do processo produtivo para evitar ao máximo a geração indevida deste produto que tem como característica uma degradabilidade muito lenta, gerando problemas ambientais e econômicos. Deve-se também atentar para a saúde do trabalhador que estiver envolvido com o processo de fabricação e aplicação destas fibras para que este use corretamente o equipamento de proteção individual e se matenha seguro das ameaças que possam vir a lhe prejudicar.

A busca pelo desenvolvimento está intrínseca ao comportamento humano, porém, devese juntamente deste aliar práticas sustentáveis, reutilizando/reaproveitando os materiais inutilizáveis em outros ciclos, para que haja uma redução de energia nos processos produtivos e, desta forma, moldar um novo comportamento à cultura do ser humano como um todo, objetivando um futuro sustentável.

\section{REFERÊNCIAS}

ARAÚJO, E. M. et al. Aproveitamento de resíduos de fibra de vidro provenientes de indústrias da Paraíba na produção de compósitos. Universidade Federal da Paraíba, RN, [200-]. Disponível em: <http://www.prac.ufpb.br/anais/Icbeu_anais/anais/tecnologia/aproveitamente.pdf> Acesso em: 1 de novembro de 2012.

ARAUJO, K. D. et al. Obtenção de compósitos de poliéster insaturado/ resíduo de fibra de vidro provenientes de indústria da Paraíba. Congresso Brasileiro de Ciência e Tecnologia em Resíduos e Desenvolvimento Sustentável, 
Rev. Elet. em Gestão, Educação e Tecnologia Ambiental (e-ISSN: 2236-1170)

Florianópolis, 2004. Disponível em: <http://www.ipen.br/biblioteca/cd/ictr/2004/ARQUIVOS\%20PDF/03/03-037.pdf> Acesso em: 12 de novembro de 2012.

BARCELLOS, I. O.; SOUZA, A. C.; SELKE, A. E.; Incorporação de Lodo Industrial em Compósitos de Resina Poliéster. Departamento de Química, Universidade Regional de Blumenau, SC, 2009. Disponível em: <http://www.scielo.br/pdf/po/v19n2/v19n2a14.pdf> Acesso em: 6 de novembro de 2012.

FONTAN, Osni. Aplicação de tramas de fibras de pupunheira (Bactris Gasipaes, H.B.K.) em compósitos híbridos com fibra de vidro em matriz de resina poliéster insaturado. Dissertação (Mestrado em Engenharia de Processos) Universidade da Região de Joinville, SC, 2009. Disponível em: <http://www.dominiopublico.gov.br/pesquisa/DetalheObraForm.do?select_action=\&co_obra=199462> Acesso em: 8 de novembro de 2012.

GRIJÓ, P. E. A.; BRUGGER, P.; Estudo Preliminar para Gestão Ambiental na Produção de Pranchas de Surfe. International Workshop Advances in Cleaner Production, SP, 2011. Disponível em: <http://www.advancesincleanerproduction.net/third/files/sessoes/5B/2/Grijo_PEA\%20-\%20Paper\%20-\%205B2.pdf> Acesso em: 9 de novembro de 2012.

JOSHI, S. V.; et al. Are natural fiber composites environmentally superior to glass fiber reinforced composites, USA, 2003. Disponível em: <https://www.msu.edu/ satish/CompositsesA-final\%20published.pdf> Acesso em: 8 de novembro de 2012.

LEITE, E. A.; Avaliação dos riscos ocupacionais provocados pela resina epóxi aos trabalhadores do setor de mármores e granitos de Cachoeiro de Itapemirim- ES. Monografia (Curso de Especialização de Perícia Médica), Universidade Gama Filho e Fundação Unimed, Vitória- ES, [200-]. Disponível em: <http://www.ebah.com.br/content/ABAAAAW3oAG/resina-epoxi> Acesso em: 9 de novembro de 2012.

MATTHEWS, F. L, RAWLINGS, R. D. Composite Materials: Engineering And Science. Chapman and Hall, UK, 1994.

MILEWSKI, J. V.; KATZ, H. S. Handbook of reinforcements for plastics. In: DOCKUM JR., J. F. (Ed.). Fiberglass. New York: Van Nostrand, 1987. p. 234-235.

NBR 10004 - Resíduos Sólidos - Classificação, 2004.

ORTH, C. M.; BALDIN, N.; ZANOTELLI, C. T. Implicações do processo de fabricação do compósito plástico reforçado com fibra de vidro sobre o meio ambiente e a saúde do trabalhador: o caso da indústria automobilística. Revista Produção Online, Florianópolis, SC, v.12, n. 2, p. 537-556, $2012 . \quad$ Disponível

em: <http://www.producaoonline.org.br/rpo/article/download/943/918> Acesso em: 12 de novembro de 2012.

OTA, W. N.; Análise de compósitos de polipropileno e fibras de vidro utilizados pela indústria automotiva nacional. Dissertação (Pós-graduação em Engenharia)- Universidade Federal do Paraná, PR, 2004. Disponível em: <http://www.pipe.ufpr.br/portal/defesas/dissertacao/058.pdf> Acesso em: 9 de novembro de 2012.

PINTO, K. N. C; MIRANDA, L. F. Processos de fabricação de plástico reforçado: poliéster reforçado com fibras de vidro. 1999. Monografia - Universidade Presbiteriana Mackenzie, São Paulo.

PINTO, N. C. K.; Reciclagem de resíduos de materiais compósitos de matriz polimérica: poliéster insaturado reforçado com fibras de vidro. Dissertação (Mestrado em Ciências na Área de Tecnologia Nuclear - Materiais) Universidade de São Paulo, 2002.2 Disponível em: <http://pelicano.ipen.br/PosG30/TextoCompleto/Kelly\%20Nanci\%20Carneiro\%20Pinto_M.pdf> Acesso em: 8 de novembro de 2012.

SILVA, H. S. P. Desenvolvimento de compósitos poliméricos com fibras de curauá e híbridos com fibras de vidro. Dissertação (Mestrado em Engenharia) - Universidade Federal do Rio Grande do Sul, Porto Alegre, 2010. Disponível em: <http://www.lume.ufrgs.br/bitstream/handle/10183/25437/000752517.pdf?sequence=1>Acesso em: 6 de novembro de 2012.

SILVA, R. A.; REZENDE, M. C. Erosão em Compósitos á Base de Fibras de Vidro/Kevlar e Resina Epóxi de uso Aeronáutico. São José dos Campos, SP, 2003. Disponível em: <http://www.scielo.br/pdf/po/v13n1/15073.pdf> Acesso em: 6 de novembro de 2012.

SOARES, R. R. et al. Influência do tipo de fibra nas propriedades de compósitos processados por moldagem por transferência de resina. Departamento de Engenharia Química da Universidade de Caxias do Sul, RS, Anais do 9o Congresso Brasileiro de Polímeros, 2007. Disponível em: < http://www.ipen.br/biblioteca/cd/cbpol/2007/PDF/581.pdf> Acesso em: 12 de novembro de 2012.

WAMBUA, P, IVENS, J, VERPOEST, I. Natural fibres: can they replace glass in fibre reinforced plastics? Elsevier Science, Belgium, 2003.

ZATTERA, A. J. et al. Reuso de Resíduos de Laminados de Fibra de Vidro na Construção Civil. Departamento de Engenharia Química Centro de Ciências Exatas e Tecnologia - Universidade de Caxias do Sul, RS, 2000. Disponível em: <www.sibr.com.br/sibr/DownloadFile?idObj=29\&tipoObj=artigo> Acesso em: 1 de novembro de 2012. 